\title{
Minimally invasive aortic valve replacement through a transverse sternotomy: a word of caution
}

\author{
B Bridgewater, R S Steyn, S Ray, T Hooper
}

\begin{abstract}
Objectives-To compare aortic valve replacement (AVR) using a minimally invasive approach through a transverse sternotomy with the established approach of median sternotomy.

Design-Retrospective, case-control study. Patients-Fourteen high risk patients (median age 78, Parsonnet score of $18 \%$ ) who underwent AVR performed through a minimally invasive transverse sternotomy were compared with a historical group of patients matched for age, sex, and Parsonnet score who underwent AVR performed through a median sternotomy by the same surgeon.
\end{abstract}

Outcome measures-Cross clamp time, total bypass time, intensive care stay, postoperative in-hospital stay, morbidity, and mortality.

Results-There were two deaths in the minimally invasive group and none in the control group (NS). The cross clamp and total bypass times were longer in the minimally invasive group (67 and $92 \mathrm{~min}$ utes $v 46$ and 66 minutes, $p<0.001)$. There was a higher incidence of re-exploration for bleeding $(14 \% v 0 \%)$ and paravalvar leaks $(21 \% v 0 \%)$ in the minimally invasive group but these differences were not significant. The minimally invasive group had a longer postoperative in-hospital stay $(p=0.025)$. The incidence of mortality or major morbidity was $43 \%$ (six of 14 ) in the minimally invasive group and $7 \%$ (one of 14) in the matched pairs $(\mathrm{p}=\mathbf{0 . 0 1 3})$.

Conclusions-AVR can be performed through a transverse sternotomy but the operation takes longer and there is an unacceptably high incidence of morbidity and mortality.

(Heart 1998;79:605-607)

Keywords: cardiac surgery; minimally invasive surgery; aortic valve replacement

There is increasing interest in performing cardiac surgery through minimally invasive approaches. ${ }^{12}$ Coronary artery bypass grafting, ${ }^{34}$ aortic valve replacement, ${ }^{56}$ and mitral valve replacement ${ }^{7}$ have been performed through approaches other than median sternotomy. Various less invasive incisions have been proposed for minimally invasive aortic valve replacement (AVR) including transverse sternotomy (D M Cosgrove, personal commu- nication, 1997) and both vertical ${ }^{5}$ and transverse $^{6}$ right parasternal approaches. Several advantages have been proposed including less postoperative pain, shorter postoperative hospital stay, and economic savings, ${ }^{5} 7$ but none has yet been proved. We evaluated our results with minimally invasive AVR performed through a transverse sternotomy and compared them with a historical group of matched patients who underwent AVR through the conventional approach of median sternotomy.

\section{Patients and methods}

Elderly patients were selected for the minimally invasive procedure as we considered that, given the potential advantages implied by the protagonists of this approach, they would possibly derive most benefit. We also wanted to avoid dividing both internal mammary arteries in younger patients, which is a necessary part of the minimally invasive approach. All patients gave informed consent before surgery. The matched pairs (age, sex, and Parsonnet score) were taken from a historical cohort of consecutive patients undergoing AVR by conventional median sternotomy performed by the same surgeon.

\section{MINIMALLY INVASIVE TECHNIQUE}

An $8 \mathrm{~cm}$ transverse incision was made across the midline, the sternum being transected at the level of the second or third intercostal space with division of both internal mammary arteries. A paediatric retractor was positioned and the sternum spread to give exposure to the ascending aorta, the superior vena cava, and the right atrial appendage. After systemic heparinisation, cardiopulmonary bypass was established at $32^{\circ} \mathrm{C}$ by cannulating the aorta with a 20 or $22 \mathrm{~F}$ gauge wire reinforced aortic cannula (Medtronic DLP, Grand Rapids, Michigan, USA). Venous drainage was established through a $24-28 \mathrm{~F}$ gauge right angled, wire reinforced cannula (Medtronic DLP) in the superior vena cava introduced directly through the wound and an additional similar cannula in the right atrium. This was introduced through the right atrial appendage through a separate stab incision made in the mid-clavicular line over the fourth intercostal space (this incision was used for an intercostal drain at the end of the procedure).

The aorta was cross clamped and the valve was replaced in the usual way with either interrupted radial or pledgeted mattress sutures of 2/0 Tycron (Davis and Geck, Wayne, New Jersey, USA). As suggested by Cosgrove and Sabik $^{5}$ commissural sutures were used to 
Table 1 Patient characteristics

\begin{tabular}{|c|c|c|c|c|c|c|c|}
\hline Patient & Age & $\operatorname{Sex}$ & Diagnosis & $\begin{array}{l}\text { Gradient } \\
\text { (mm Hg) }\end{array}$ & $\begin{array}{l}\text { Ejection } \\
\text { fraction }\end{array}$ & $\begin{array}{l}\text { Parsonnet } \\
\text { score }\end{array}$ & Status \\
\hline \multicolumn{8}{|c|}{ Minimally invasive group } \\
\hline 1 & 81 & $\mathrm{~F}$ & AS & 88 & Good & 26 & Elective \\
\hline 2 & 83 & $\mathrm{~F}$ & AS & 80 & Good & 26 & Elective \\
\hline 3 & 79 & $\mathrm{~F}$ & AS & 80 & Good & 24 & Urgent \\
\hline 4 & 78 & $\mathrm{~F}$ & AS & 106 & Good & 25 & Urgent \\
\hline 5 & 76 & $\mathrm{~F}$ & AS/AR & 134 & Good & 18 & Urgent \\
\hline 6 & 77 & $\mathrm{~F}$ & AS/AR & 106 & Good & 26 & Elective \\
\hline 7 & 89 & $\mathrm{~F}$ & AS & 100 & Good & 7 & Elective \\
\hline 8 & 60 & $\mathrm{M}$ & AS & 120 & Moderate & 9 & Elective \\
\hline 9 & 62 & $\mathrm{~F}$ & AS & 114 & Good & 10 & Elective \\
\hline 10 & 71 & $\mathrm{M}$ & AS & 100 & Good & 28 & Elective \\
\hline 11 & 80 & $\mathrm{~F}$ & AS & 130 & Good & 11 & Elective \\
\hline 12 & 74 & $\mathrm{~F}$ & AS & 90 & Moderate & 13 & Elective \\
\hline 13 & 79 & $\mathrm{M}$ & AS & 50 & Poor & 21 & Elective \\
\hline 14 & 78 & M & AS & 84 & Good & 21 & Elective \\
\hline \multicolumn{8}{|c|}{ Matched pairs } \\
\hline 1 & 72 & $\mathrm{~F}$ & AS & 112 & Good & 16 & Elective \\
\hline 2 & 71 & $\mathrm{~F}$ & AS \& CAD & 83 & Good & 16 & Elective \\
\hline 3 & 77 & $\mathrm{~F}$ & AS & 126 & Good & 20 & Elective \\
\hline 4 & 78 & $\mathrm{~F}$ & AS \& CAD & 85 & Good & 21 & Elective \\
\hline 5 & 75 & $\mathrm{~F}$ & AS & 108 & Good & 18 & Elective \\
\hline 6 & 77 & $\mathrm{~F}$ & AS & 120 & Good & 20 & Elective \\
\hline 7 & 87 & $\mathrm{~F}$ & AS & 90 & Good & 18 & Elective \\
\hline 8 & 60 & M & AS & 70 & Moderate & 14 & Elective \\
\hline 9 & 67 & $\mathrm{~F}$ & AS & 127 & Good & 8 & Elective \\
\hline 10 & 69 & M & AS/AR & 115 & Good & 8 & Elective \\
\hline 11 & 76 & $\mathrm{~F}$ & AS & 96 & Good & 21 & Elective \\
\hline 12 & 70 & $\mathrm{~F}$ & AS/AR & 112 & Good & 13 & Urgent \\
\hline 13 & 77 & M & AS & 121 & Good & 21 & Elective \\
\hline 14 & 77 & M & AS & 81 & Good & 19 & Urgent \\
\hline
\end{tabular}

AS, aortic stenosis; AR, aortic regurgitation; CAD, coronary artery disease.

improve access to the aortic annulus. Once the valve was inserted, the aortotomy was closed and a vent placed in the ascending aorta. The heart was de-aired through the ascending aorta and transoesophageal echocardiography was used routinely to assess aortic prosthestic function and to confirm complete de-airing before discontinuing cardiopulmonary bypass. A drain was inserted through the stab incision used for the right atrial cannula and positioned to straddle the mediastinum and both pleural cavities. The sternotomy was closed with two interrupted loops of stainless steel wire.

CONVENTIONAL TECHNIQUE

Before minimally invasive AVR was introduced all patients underwent conventional AVR performed through a median sternotomy using cardiopulmonary bypass established by aortic and two stage venous cannulation. Valve insertion techniques were similar to those used in the minimally invasive procedure. Transoesophageal echocardiography was not used.

Table 2 Operative details in the minimally invasive group

\begin{tabular}{|c|c|c|c|c|c|}
\hline Patient & Valve & $\begin{array}{l}\text { Cross } \\
\text { clamp } \\
\text { (minutes) }\end{array}$ & $\begin{array}{l}\text { Bypass } \\
\text { (minutes) }\end{array}$ & Sutures & $T O E$ \\
\hline 1 & CE 19 & 74 & 105 & IR & Satisfactory \\
\hline 2 & CE 19 & 47 & 67 & IR & Satisfactory \\
\hline 3 & CE 19 & 56 & 80 & IR & Satisfactory \\
\hline 4 & CE 21 & 51 & 69 & IR & Satisfactory \\
\hline 5 & CE 19 & 65 & 92 & TP & Satisfactory \\
\hline 6 & CE 21 & 95 & 125 & IR & Satisfactory \\
\hline 7 & CE 21 & 45 & 60 & IR & Satisfactory \\
\hline 8 & StJ 21 & 72 & 95 & IR & Satisfactory \\
\hline 9 & StJ 19 & 71 & 97 & IR & Satisfactory \\
\hline 10 & CE 21 & 57 & 86 & ТP & Satisfactory \\
\hline 11 & CE 21 & 67 & 95 & ТP & Satisfactory \\
\hline 12 & CE 21 & 59 & 85 & ТP & Satisfactory \\
\hline 13 & CE 23 & 84 & 130 & TP & Satisfactory \\
\hline 14 & CE 23 & 90 & 108 & IR & Satisfactory \\
\hline
\end{tabular}

Satisfactory, no leak and adequate de-airing.

TOE, transoesophageal echocardiography; CE, Carpentier Edwards; StJ, St Jude; TP, Teflon pledget; IR, interrupted radial.
MYOCARDIAL PROTECTION

Cardiopulmonary bypass was conducted at $32^{\circ} \mathrm{C}$ and myocardial protection established by cold intermittent antegrade cardioplegia.

STATISTICAL ANALYSIS

Mortality and the incidence of complications in the two groups were compared with the $\chi^{2}$ test. The length of cross clamp and bypass times were compared with the Student's $t$ test. The number of days in the intensive care unit and postoperative in-hospital stay were compared with the Mann-Whitney $U$ test. As the numbers were small, we compared the incidence of mortality and major morbidity combined between the groups with the $\chi^{2}$ test.

\section{Results}

PATIENT CHARACTERISTICS

Table 1 shows the characteristics of the 14 patients (10 women) who underwent minimally invasive AVR. The median age was 78 years (range 60-89) and the median Parsonnet score $18 \%$ (range $7-28 \%$ ). Twelve had aortic stenosis alone and two had combined stenosis and regurgitation. Eleven procedures were elective and three urgent. The ejection fraction was assessed on the left ventriculogram if available at angiography or alternatively by echocardiography. An ejection fraction of more than $50 \%$ was defined as good, $30-50 \%$ as moderate, and less than $30 \%$ as poor.

Patients were matched for sex and as closely as possible for age and Parsonnet score (table 1). This group had a median age of 76 years (range 60-87) and Parsonnet score of $18 \%$ (range 8-26\%). Two patients underwent concomitant coronary artery bypass surgery. All patients had aortic stenosis and two had both stenosis and regurgitation.

\section{OPERATIVE DETAILS}

Table 2 shows the operative details of the minimally invasive group. The mean cross clamp and bypass times for the minimally invasive group were 67 minutes (range 45-95) and 92 minutes (60-130) compared with 46 minutes (range 35-60) and 66 minutes (50-95) for the control group $(p<0.001)$. The two patients undergoing combined AVR and coronary artery bypass surgery in the matched pairs group were excluded from these calculations. Exposure was not always ideal through a second interspace transverse sternotomy. Specifically, access to the right atrial appendage proved problematic in one patient and in others access to the aortic annulus, particularly for tying down of valve sutures, proved difficult especially in deep chested patients.

POSTOPERATIVE DETAILS

Table 3 shows mortality and morbidity in the minimally invasive group. There were two deaths in the minimally invasive group and none in the control group $(p=0.16)$. One death was caused by a gastrointestinal bleed and the other to multisystem failure. The median intensive care stay was one day (range 1-40) for the minimally invasive group and one day (range 1-3) for the control group 
Table 3 Postoperative details of the minimally invasive group

\begin{tabular}{lccll}
\hline Patient & $\begin{array}{c}\text { ICU stay } \\
\text { (days) }\end{array}$ & $\begin{array}{l}\text { Hospital } \\
\text { stay (days) }\end{array}$ & Died & Complications \\
\hline 1 & 1 & 6 & No & Nil \\
2 & 1 & 28 & No & Temporary pacing wire \\
3 & 1 & 9 & No & Paraprosthetic leak \\
4 & 1 & 11 & No & Nil \\
5 & 1 & 9 & No & Nil \\
6 & 14 & 19 & Yes & Gastrointestinal bleed, laparotomy, ARDS died \\
7 & 3 & 13 & No & Re-explored-excessive bleeding \\
8 & 1 & 8 & No & Nil \\
9 & 1 & 8 & No & Nil \\
10 & 30 & 47 & No & $\begin{array}{c}\text { Re-explored, respiratory failure, tracheostomy, } \\
\text { paraprosthetic leak }\end{array}$ \\
11 & 1 & 21 & No & Intraoperative bleeding from posterior aspect of \\
& & & aortic root \\
12 & 40 & 40 & Yes & $\begin{array}{c}\text { Endotoxaemia, multiorgan failure, haemodialysis, } \\
\text { tracheostomy, died }\end{array}$ \\
13 & 2 & 12 & No & Intraoperative bleeding from posterior aspect of \\
& & & & aortic root \\
14 & 1 & 16 & No & CVA-paraprosthetic leak \\
\hline
\end{tabular}

ARDS, acute respiratory distress syndrome; CVA, cerebrovascular accident.

$(\mathrm{p}=0.194)$. The median in-hospital stay was 12 days (range 6-47) for the minimally invasive group and eight days (range 6-18) for the control group $(p=0.025)$. Two patients in the minimally invasive group were re-explored for excessive bleeding compared with none in the control group. Three patients in the minimally invasive group developed new paravalvar leaks but reoperation was not required; none was detected in the control group ( $\mathrm{p}=0.07)$.

Two patients in the minimally invasive group died and four had major morbidity (one paraprosthetic leak, one perioperative cerebrovascular accident and a paraprosthetic leak, and two re-explorations for bleeding, one of these patients developed respiratory failure and a paraprosthetic leak). One patient had major morbidity in the control group (renal failure not requiring dialysis and his superficial wound was resutured $)(p=0.013)$.

\section{Discussion}

In the past few years there has been increasing interest in performing cardiac surgery through incisions other than median sternotomy. Less invasive coronary artery surgery performed through either a median sternotomy ${ }^{6}$ or a left anterior thoracotomy ${ }^{2}$ without cardiopulmonary bypass has been carried out with good results. There is still controversy about the indications, if any, for less invasive coronary artery surgery. ${ }^{1}$

Valve surgery can also be performed through less invasive surgical approaches..$^{5-7}$ It has been suggested that both aortic and mitral valves can be replaced with good exposure, and that smaller incisions reduce pain, the risk of wound infection, and blood loss. It has also been suggested that patients recover more rapidly and are discharged from hospital earlier, reducing total hospital costs, and that a minimally invasive approach is cosmetically more attractive to patients. ${ }^{7}$ Minimally invasive valve operations do not offer the theoretical attraction of avoiding cardiopulmonary bypass and its inherent complications in the same way that minimally invasive coronary artery surgery does.

No large series of valve replacement using a minimally invasive approach has been reported and none of the potential advantages has been found in randomised studies, although there is great interest among surgeons in these new techniques. We have analysed our experience of the first 14 patients who underwent minimally invasive AVR performed through a transverse sternotomy.

AVR performed through a median sternotomy is a well established technique, with an operative mortality for isolated AVR of $4.5 \%$ in the United Kingdom (UK Cardiac Surgical Register, Society of Cardiothoracic Surgeons of Great Britain and Ireland). Mortality in our minimally invasive group was $14 \%(95 \%$ confidence interval 6 to 44 ); however, this was a high risk, elderly group. Mortality was not significantly higher than in the matched pairs group in which no deaths occurred.

There was also a high morbidity in the minimally invasive group: two patients were reexplored for bleeding, three had paraprosthetic leaks, and one had a cerebrovascular accident. None of the leaks was present on intraoperative echocardiography but developed in the early postoperative period, presumably because of stitches cutting out as a result of poorer operative exposure from the minimally invasive approach. The subsequent use of pledgeted sutures did not prevent such leaks in the later part of the series. None of the paraprosthetic leaks was sufficiently severe to require reexploration. There were no paraprosthetic leaks in the matched pairs group. The paraprosthetic leak rate after aortic valve surgery should be low, with reported rates of between $1 \%$ and $10 \%{ }^{89}$ The incidence of combined mortality or major morbidity is higher in the minimally invasive group than in the controls, and this is reflected in the statistically longer postoperative in-hospital stay in the minimally invasive group.

We do not know to what extent these suboptimal initial results reflect the learning curve associated with a new technique or the technique itself, but we have seen as many problems in the last few patients of our small series as we did in the first. The relative advantages and disadvantages of the minimally invasive approach over established techniques will be established only by randomised clinical trials, but we have not been sufficiently impressed by our early results to pursue such a study. We have discontinued using this approach for AVR and await the findings of other workers with interest.

1 Westaby S, Benetti FJ. Less invasive coronary surgery: consensus from the Oxford meeting. Ann Thorac Surg 1996;62:924-31.

2 Calafiore AM, Angelini GD, Bergsland J, et al. Minimally invasive coronary artery bypass grafting. Ann Thorac Surg 1996;62:1545-8.

3 Acuff TE, Landreneau RJ, Griffith BP, et al. Minimally invasive coronary artery bypass grafting. Ann Thorac Surg 1996;61:135-7.

4 Calafiore AM, Di Giammarco G, Teodori G, et al. Left anterior descending coronary artery bypass grafting via left anterior small thoracotomy without cardiopulmonary bypass. Ann Thorac Surg 1996;61:1658-65.

5 Cosgrove DM, Sabik JF. Minimally invasive approach for aortic valve operations. Ann Thorac Surg 1996;62:596-7.

6 Bennetti FJ, Mariani MA, Rizardi JL, et al. Minimally invasive aortic valve replacement. F Thorac Cardiovasc Surg 1997:113:806-7.

7 Navia JL, Cosgrove DM. Minimally invasive mitral valve operations. Ann Thorac Surg 1996;62:1542-4.

8 Kirklin JW, Barratt-Boyes BC. Cardiac surgery. 2nd ed. New York: Churchill Livingstone, 1993:538-44.

9 Jacobs ML, Fowler BN, Vezeridis MP, et al. Aortic valve Jacobs ML, Fowler $\mathrm{BN}$, Vezeridis MP, et al. Aortic valve
replacement: a 9 year experience. Ann Thorac Surg 1980;30:439-47. 